\title{
Welcome to ACTA IMEKO
}

\section{Pasquale Daponte}

Department of Engineering, University of Sannio, Palazzo Bosco-Lucarelli, Piazza Roma, 82100 Benevento, Italy

Keywords: Journal; IMEKO; President Elect

Citation: Pasquale Daponte, Welcome to ACTA IMEKO, Acta IMEKO, vol. 1, no. 1, article 3, July 2012, identifier: IMEKO-ACTA-01(2012)-01-03

Editor: Paul Regtien, Measurement Science Consultancy, The Netherlands

Copyright: @ 2012 IMEKO. This is an open-access article distributed under the terms of the Creative Commons Attribution 3.0 License, which permits unrestricted use, distribution, and reproduction in any medium, provided the original author and source are credited

Corresponding author: Pasquale Daponte, e-mail: daponte@unisannio.it

Welcome to ACTA IMEKO! ACTA IMEKO is a new scientific journal exploring all the fields of measurement science; a science that drives and underpins much of what we do and experience in our everyday lives, though often unseen and beyond our awareness.

ACTA IMEKO was established to provide reviews of current topics in measurement science in order to share the latest research results among scientists of all over the world, and to be a reference point of the state of art in the measurement field for all people involved directly or indirectly in measurements and to assist them in the translation of science into practice.

ACTA IMEKO aims to conduct science cooperation across the world to bolster confidence in the identification of potential measurement and testing requirements at an early stage during research, innovation or development, so that measurement solutions can be developed in a timely manner in any technical field.

ACTA IMEKO is a free on-line peer-reviewed journal. By making it readily available online, IMEKO hopes to reach the largest number of readers, including those who cannot afford printed journals and online subscriptions in countries and regions with little or no library resources, but only Internet access.

ACTA IMEKO is a great opportunity for all IMEKO Technical Committees to offer the contributions of the events they organize to a wider audience. Revised papers, after presentation to an IMEKO event, are strongly solicited. Thanks to ACTA IMEKO the penetration of our organization in the measurement science international community may improve considerably. This is a further step in the IMEKO policy toward an effective globalization of knowledge. I wish to thank all the IMEKO officers that made this result possible.

I am sure that this young journal will attract young authors wishing to contribute to the success of this initiative, although I am aware that it requires much more active participation by the international academic community. Many scientists in the measurement field have shared and supported this project by joining the journal's scientific committee, forming a selected pool of reviewers for the incoming contributions; this is a promising start. I hope you will find the journal interesting and will actively contribute to its development. 